\title{
Remote-Controlled Automatic Injection Versus Manual Injection in Ictal SPECT of Seizure Patients: Experience from a Children's Hospital
}

\section{$\mathbf{S}$} tion will benefit from surgical removal of the seizure focus in the brain, if the seizure focus can be identified. The seizure focus has to be localized in one hemisphere only. This is referred to as refractory complex partial epilepsy.
The problem is that identification of the seizure focus is not easily accomplished. One way to identify the seizure focus is by electrocorticography, which involves the placement of a grid of electrodes directly on the surface of the brain. This procedure is costly and invasive. Cerebral perfusion
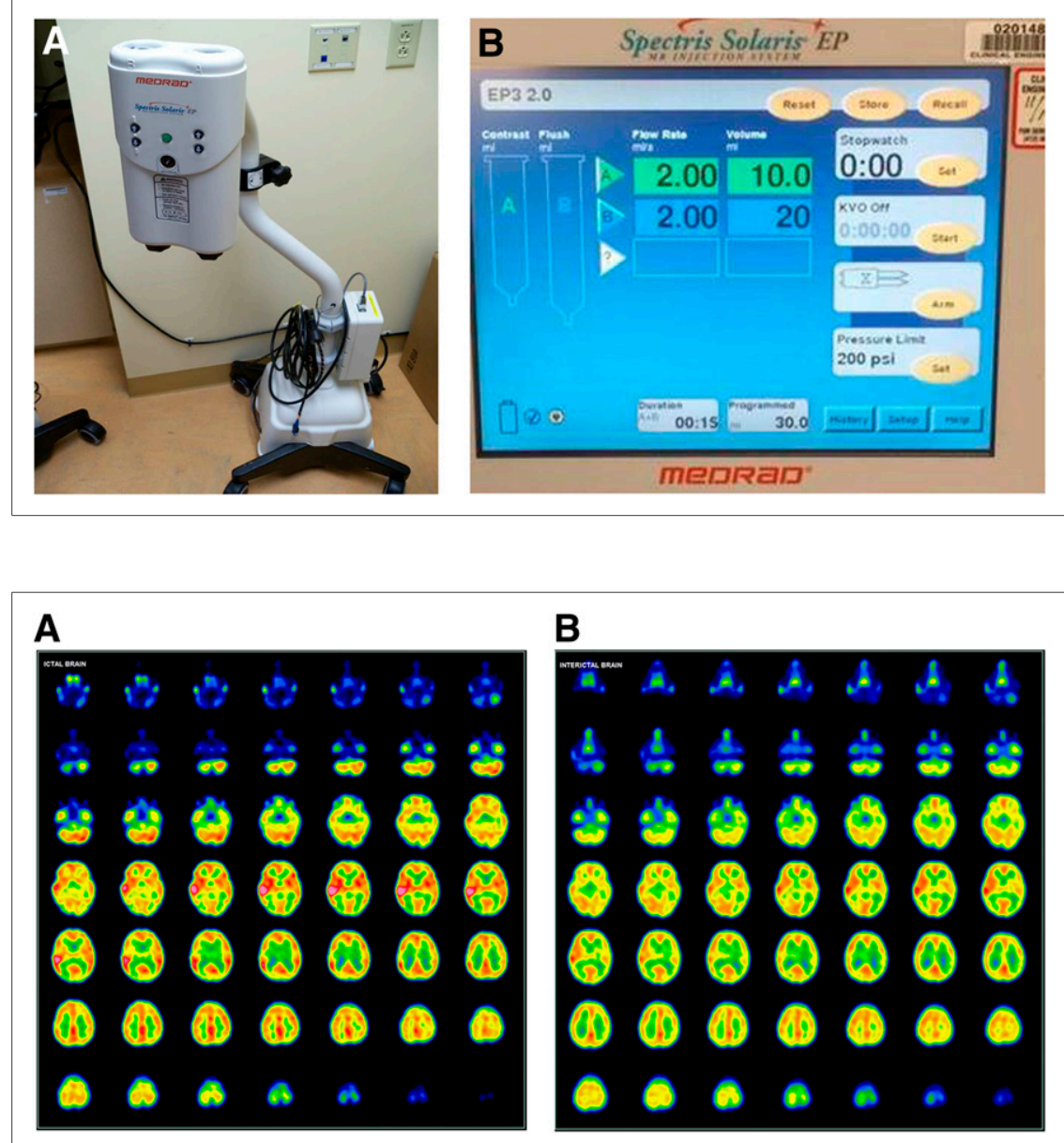

FIGURE 1. Remote-controlled automatic injector (A) and its display (B) (Spectris Solaris EP; Medrad).
Received Jul. 18, 2014; accepted Jul. 18, 2014

For correspondence or reprints contact: Ashley Crawford, 331 Woodlands Rd., Evans City, PA 16033.

E-mail: ancst17@mail.rmu.edu

Published online Aug. 14, 2014.

COPYRIGHT (c) 2014 by the Society of Nuclear Medicine and Molecular Imaging, Inc.

DOI: $10.2967 /$ jnmt.114.145854 imaging is a much less invasive and costly technique that can be used to identify the seizure focus. The 2 cerebral perfusion agents that can be used for this study are ${ }^{99 \mathrm{~m}} \mathrm{Tc}-$ exametazine and ${ }^{99} \mathrm{~m} \mathrm{Tc}$-bicisate.

Cerebral perfusion images of the ictal phase (seizure phase) and interictal phase (when the patient is not having a seizure) need to be acquired and compared. The epileptogenic focus (seizure focus) has to be exactly and 
precisely identified. This is where the seizure originatesthe area of the brain that needs to be removed surgically. To identify the seizure focus, a cerebral perfusion agent must be administered to the patient at the very onset of a seizure. If the radiopharmaceutical is administered quickly at onset, the seizure focus will be identified. If the radiopharmaceutical is not administered quickly enough, the scan may not identify the seizure because the seizure event has spread throughout the brain.

Patients need to be hospitalized for the injection and acquisition of the ictal study. The patients will be monitored via video and electroencephalography for any signs of seizure activity. The onset of a seizure can occur at any time. For the ictal study, the radiopharmaceutical can be administered by a remote-controlled automatic injector (Fig. 1) or by manual injection. Manual injection means that when the electroencephalography technologist sees that a seizure has started, the technologist sends someone quickly to the patient's room to give the radiopharmaceutical injection. When manual injection is used, the radiopharmaceutical is administered through the intravenous line at the onset of the seizure, usually by a nurse. With the remote-controlled automatic injector, the dose is administered remotely when the seizure starts.

Why should a remote-controlled automatic injector be used? Latency time, which is the time between seizure onset and injection, is crucial. The success of imaging the epileptogenic focus lies in injecting the radiopharmaceutical as soon as the patient starts to seize. The average seizure lasts 1-2 min. If the ictal scan tracer is not injected quickly, the scan will reflect seizure spread and will not provide an accurate location for surgery. A time delay can occur while the nurse is being notified, the lead-shielded radiotracer container opened, the syringe removed, and the syringe inserted into the intravenous line port. The use of a remotecontrolled automatic injector allows the intravenous injection to be administered in a timelier manner from a nearby room.

How does the remote-controlled automatic injector work? It contains 2 syringes. One syringe is the radiopharmaceutical ( ${ }^{99 \mathrm{~m}} \mathrm{Tc}$-exametazine or ${ }^{99 \mathrm{~m}} \mathrm{Tc}-$ bicisate), and one is the agent that keeps the intravenous line patent. Because of the 30-min shelf life of exametazine, methylene blue is added to extend the shelf life to $4 \mathrm{~h}$ if this agent is used. The radiopharmaceutical is reloaded every $4 \mathrm{~h}$. When the seizure occurs, the radiopharmaceutical is administered at a rate of $3 \mathrm{~mL}$ per second.
We retrospectively analyzed 2 groups of pediatric patients who underwent ictal SPECT with ${ }^{99 \mathrm{~m} T c-e x a m e t a-}$ zine (Fig. 2). There were a total of 74 pediatric patients who were injected using either the automatic injector or manual injection. Thirty-three patients were injected using the automatic injector, and 41 were manually injected. Other parameters were reasonably comparable, such as the seizure duration, radiopharmaceutical dose, and injection-toimaging time. We compared the success of identifying the epileptogenic focus between these 2 subsets. When latency time was compared, the automatic injector averaged $15 \mathrm{~s}$, with a range of 4-20 s. The manual injection averaged $25 \mathrm{~s}$, with a range of 14-35 s. The automatic injector correctly identified the epileptogenic focus in 30 of the 33 patients (91\%). The epileptogenic focus was identified in only 20 of the 41 patients who were injected using the manual method (49\%).

In conclusion, for identification of the seizure focus in patients with refractory complex partial epilepsy by cerebral perfusion SPECT, we recommend automatic injection over manual injection of the radiopharmaceutical for the ictal scan. In the future, the remote-controlled automatic injector may potentially drive down the cost of identifying a seizure focus by reducing the number of repeated imaging studies and decreasing the length of the hospital stay.

\section{DISCLOSURE}

No potential conflict of interest relevant to this article was reported.

Ashley Crawford Robert Morris University Pittsburgh, Pennsylvania

Scott M. Conners Michael Czachowski Ashok Muthukrishnan UPMC Children's Hospital of Pittsburgh Pittsburgh, Pennsylvania

\section{BIBLIOGRAPHY}

Habibian MR, Delbeke D, Martin WH, Vitola JV, Sandler MP. Nuclear Medicine Imaging: A Teaching File. 2nd ed. Philadelphia, PA: Lippincott Williams and Wilkins; 2009.

Mannella K, Steiner C, Sheetz M. Radiation safety issues for use of an automatic injector for epilepsy ictal brain. Presented at: Health Physics Society Midyear Meeting; January 2013; Scottsdale, AZ. 